\title{
Poly(2,5-benzimidazole) nanofibers prepared by reaction-induced crystallization
}

\author{
Kazuya Kimura ${ }^{1}$, Jin Gong ${ }^{1}$, Shin-ichiro Kohama ${ }^{1}$, Shinichi Yamazaki ${ }^{1}$, Tetsuya Uchida ${ }^{2}$ and Kunio Kimura ${ }^{1}$ \\ Morphological control of poly(2,5-benzimidazole) (PBI) was examined by reaction-induced phase separation of oligomers \\ during polymerization to prepare nanofibers. Three monomers, 3,4-diaminobenzoic acid (DABA), 3,4-diacetoamidebenzoic \\ acid (DAcBA) and phenyl 3,4-diaminobenzoate (PDAB), were used to synthesize PBI. Polymerizations were carried out at \\ $350{ }^{\circ} \mathrm{C}$ in a mixture of dibenzyltoluene isomers. Polymerization of DABA yielded spheres with plate-like crystals on their surface. \\ Polymerization of DAcBA yielded almost no precipitates because of the high solubility of DAcBA oligomers. By contrast, \\ polymerization of PDAB yielded aggregates of PBI nanofibers (of which the average diameter was $\sim 60 \mathrm{~nm}$ ), which resembled \\ nonwoven fabrics. These fibers were formed by precipitation of (2,5-benzimidazole) oligomers and their subsequent \\ polymerization into a developing crystal structure. The structure of the monomer significantly influenced the morphology \\ of the PBI product, and PDAB was preferable for the preparation of PBI nanofibers. The temperature of $10 \% \mathrm{~N}_{2}$ weight loss \\ in these nanofibers was in the range of $634-644{ }^{\circ} \mathrm{C}$ and they were thermally stable.
}

Polymer Journal (2010) 42, 375-382; doi:10.1038/pj.2010.20; published online 17 March 2010

Keywords: heterocyclic polymer; nanofiber; phase separation; polybenzimidazole

\section{INTRODUCTION}

Heterocyclic aromatic polymers have been developed as high-performance materials. Among them, polybenzimidazoles are one of the most successful materials, because of their high chemical resistance, flame retardance, radiation stability and excellent mechanical strength, which is retained over a wide temperature range. ${ }^{1-10}$ Much effort has been devoted to fabricating polybenzimidazoles for practical uses and some of them are now commercially available. ${ }^{11,12}$ Polybenzimidazoles do not melt at decomposition temperatures and they are usually soluble only in strong acids such as sulfuric acid and methanesulfonic acid. Therefore, they are poorly processable and present a conundrum of high performance versus tractability.

Recently, nanoscale materials have received much attention and micrometer- and nanometer-scale morphological control has been eagerly sought. Although nanofibers of poly[2,2'-(1,3-phenylene)-5, $5^{\prime}$ bibenzimidazole] have been produced by electrospinning, ${ }^{13,14}$ this method is limited by the intractability of the polymers. Efforts to improve their poor processability have been generally directed toward the chemical modification of polymer backbones, including the substitution at the reactive $\mathrm{N}-\mathrm{H}$ sites in the imidazole moiety. ${ }^{15-20}$ However, structural modification always imparts solubility at the cost of sacrificing desirable properties derived from the rigid polymer structure. Isothermal polymerizations can induce a phase separation in a homogeneous solution. Phase separation is determined by the miscibility of the oligomer and the solvent, and is related to the decline in solution-mixing entropy. The interplay between polymerization and phase separation is responsible for phase separation modes that are crystallization and liquid-liquid phase separations. Hence, reaction-induced phase separation has been extensively studied in an effort to control morphology by tuning the polymerization conditions. ${ }^{21-27}$ We previously studied the morphological control of poly[2,6-(1,4-phenylene)-benzobisimidazole] by reaction-induced phase separation, and we reported the preparation of brush-like crystals. $^{28}$ This brush-like morphology was quite unique, but nanofibers had not yet been prepared. It has been reported that the chemical structure of the end groups of precipitated oligomers significantly influences morphology, ${ }^{29-31}$ and the structural regularity of the end groups is of great importance in forming clear crystals. In the case of AA-BB-type polybenzimidazoles, it is difficult to ensure the structural regularity of the end groups of phaseseparated oligomers. AB-type polybenzimidazoles prepared from self-polymerizable monomers are more desirable for preparing clear crystals. Therefore, we next aimed to control the morphology of, and ultimately to prepare nanofibers from, poly(2,5-benzimidazole) (PBI) using phase separation of oligomers during polymerization of 3,4-diaminobenzoic acid (DABA), 3,4-diacetoamidebenzoic acid (DAcBA) and phenyl 3,4-diaminobenzoate (PDAB), as shown in Scheme 1.

${ }^{1}$ Graduate School of Environmental Science, Okayama University, Okayama, Japan and ${ }^{2}$ Graduate School of Natural Science and Technology, Okayama University, Okayama, Japan

Correspondence: Professor K Kimura, Graduate School of Environmental Science, Okayama University, 3-1-1 Tsushima-naka, Okayama 700-7530, Japan.

E-mail: polykim@cc.okayama-u.ac.jp

Received 19 November 2009; revised 27 January 2010; accepted 4 February 2010; published online 17 March 2010 


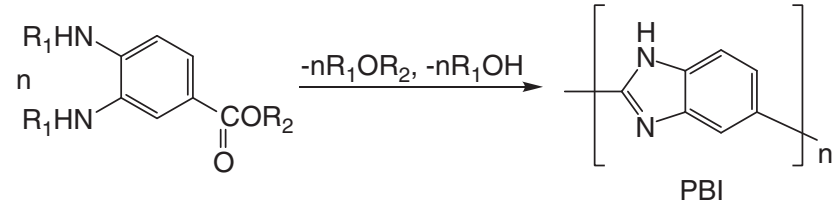

$$
\begin{aligned}
& \text { DABA: } \mathrm{R}_{1}=\mathrm{H}, \mathrm{R}_{2}=\mathrm{H} \\
& \text { DAcBA: } \mathrm{R}_{1}=\mathrm{COCH}_{3}, \mathrm{R}_{2}=\mathrm{H} \\
& \text { PDAB: } \mathrm{R}_{1}=\mathrm{H}, \mathrm{R}_{2}=\mathrm{C}_{6} \mathrm{H}_{5}
\end{aligned}
$$

Scheme 1 Synthesis of PBI.

\section{EXPERIMENTAL PROCEDURE}

\section{Materials}

DABA and 3,4-dinitrobenzoic acid were purchased from TCI (Tokyo, Japan). DABA was purified by recrystallization from water with a small amount of activated charcoal. $N, N$-Dimethylacetamide, $N, N$-dimethylformamide, tetrahydrofuran (THF), thionyl chloride, acetyl chloride and ethyl acetate were purchased from Sigma-Aldrich (Tokyo, Japan). $N, N$-Dimethylacetamide and $N, N$-dimethylformamide were purified by distillation under reduced pressure over calcium hydride. THF and ethyl acetate were purified by distillation over calcium hydride. Thionyl chloride and acetyl chloride were used as received. A mixture of dibenzyltoluene isomers (DBT) was purchased from Matsumura Oil (Osaka, Japan) (trade name: Barrel Therm 400, molecular weight (MW): 270, boiling point: $\left.390^{\circ} \mathrm{C}\right)$ and purified by vacuum distillation $\left(160-165^{\circ} \mathrm{C} /\right.$ $0.3 \mathrm{~mm} \mathrm{Hg}$ ). Liquid paraffin (LPF) was purchased from Nacalai Tesque (Kyoto, Japan) and purified by vacuum distillation $\left(200-215^{\circ} \mathrm{C} / 0.35 \mathrm{~mm} \mathrm{Hg}\right)$.

\section{Measurements}

Morphology was observed using a Hitachi S-3500N scanning electron microscope (Hitachi, Tokyo, Japan) at $20 \mathrm{kV}$ and a JEOL 2000EX transmission electron microscope (JEOL, Tokyo, Japan) at $200 \mathrm{kV}$. Average-shaped parameters of the products were determined by taking the average of over 200 observation values on scanning electron microscope. Infrared (IR) spectra were measured on a JASCO FT/IR-410 spectrometer (JASCO, Tokyo, Japan). The inherent viscosity $\left(\eta_{\text {inh }}\right)$ of the polymers was measured in $97 \%$ sulfuric acid at a concentration of $0.2 \mathrm{~g} \mathrm{dl}^{-1}$ at $30^{\circ} \mathrm{C}$ with an Ostwald viscometer. The thermal stability of the polymers was evaluated by thermogravimetric analysis on a Perkin Elmer (Waltham, MA, USA) TGA-7A at a scanning rate of $20^{\circ} \mathrm{C} \mathrm{min}-1$ in $\mathrm{N}_{2}$. Wide-angle X-ray scattering patterns were determined on a Rigaku Miniflex (Matsumoto, Japan) with nickel-filtered $\mathrm{CuK} \alpha$ radiation with a scanning rate of 1 degree $\mathrm{min}^{-1}$. Matrix-assisted laser desorption ionization time-of-flight mass spectrometry was performed on a Bruker Daltonics AutoFLEX (Billerica, MA, USA) matrix-assisted laser desorption ionization time-of-flight mass spectrometry system operating with a $337 \mathrm{~nm} \mathrm{~N} \mathrm{~N}_{2}$ laser. Spectra were obtained in the linear positive mode with an accelerating potential of $20 \mathrm{kV}$. Masses were calibrated with angiotensin (MW 1296.69) and insulin B (MW 3496.96) using a Sequazyme peptide mass standard kit (Applied Biosystems, Carlsbad, CA, USA). Samples were prepared by the evaporation-grinding method, and then measured in dithranol as a matrix doped with potassium trifluoroacetate according to the previously reported procedure. ${ }^{32}$

\section{Synthesis of DAcBA}

DABA $(3.0 \mathrm{~g}, 0.020 \mathrm{~mol})$ and $\mathrm{N}, \mathrm{N}$-Dimethylacetamide $(50 \mathrm{ml})$ were placed in a flask and the solution was allowed to cool at $0{ }^{\circ} \mathrm{C}$. A solution of acetyl chloride $(2.9 \mathrm{ml}, 0.041 \mathrm{~mol})$ in $N, N$-dimethylacetamide $(10 \mathrm{ml})$ was added to the solution at $0{ }^{\circ} \mathrm{C}$ in $\mathrm{N}_{2}$. The mixture was stirred at $0{ }^{\circ} \mathrm{C}$ for $1 \mathrm{~h}$ and then at $25^{\circ} \mathrm{C}$ for $12 \mathrm{~h}$. The mixture was poured into water and a white precipitate was collected by filtration. Recrystallization from methanol resulted in DAcBA crystals $(3.5 \mathrm{~g}, 75 \%)$. Melting point: $239^{\circ} \mathrm{C}$. Anal. Calcd. for $\mathrm{C}_{11} \mathrm{H}_{12} \mathrm{O}_{4} \mathrm{~N}_{2}$ : C, 55.93; H, 5.12; N, 11.86. Found: C, 55.40; H, 5.07; N, 11.36. ${ }^{1} \mathrm{H}$ NMR $\left(300 \mathrm{MHz}\right.$, DMSO- $\left.d_{6}\right): \delta 12.9-12.8(\mathrm{~s}, 1 \mathrm{H}), 9.5-9.4(\mathrm{~d}, 2 \mathrm{H}), 8.15-8.05(\mathrm{~d}$, $1 \mathrm{H})$, 7.85-7.75 (d, 1H), 7.7-7.6 (m, 1H), 2.15-2.05 (d, 6H). IR (KBr, cm $\left.{ }^{-1}\right)$ :
$3281,1698,1628,1593,1558,1527,1428,1376,1310,1225,1208,908,769,727$, $672,617,587,545$.

\section{Synthesis of PDAB}

3,4-Dinitrobenzoic acid $(10 \mathrm{~g}, 0.047 \mathrm{~mol})$ and thionyl chloride $(50 \mathrm{ml})$ were placed into a flask and $\mathrm{N}, \mathrm{N}$-dimethylformamide $(1.0 \mathrm{ml})$ was added dropwise to this solution. The reaction mixture was then stirred at $25^{\circ} \mathrm{C}$ for $12 \mathrm{~h}$ in $\mathrm{N}_{2}$. Crude 3,4-dinitrobenzoyl chloride was obtained by the evaporation of excess thionyl chloride and a subsequent extraction with dried $n$-hexane. Crude 3,4dinitrobenzoyl chloride $(10.8 \mathrm{~g}, 0.047 \mathrm{~mol})$, phenol $(5.3 \mathrm{~g}, 0.056 \mathrm{~mol})$ and dried THF $(100 \mathrm{ml})$ were placed in a flask and the solution was allowed to cool at $0{ }^{\circ} \mathrm{C}$. A solution of triethylamine $(7.8 \mathrm{ml}, 0.056 \mathrm{~mol})$ in THF $(20 \mathrm{ml})$ was added dropwise to the mixture under stirring at $0{ }^{\circ} \mathrm{C}$ in $\mathrm{N}_{2}$. The mixture was stirred at $0{ }^{\circ} \mathrm{C}$ for $1 \mathrm{~h}$. The precipitate was removed by filtration, and THF was evaporated to afford yellow solids. The yellow solids were washed with water and dried. Recrystallization from methanol yielded phenyl 3,4-dinitrobenzoate crystals $(4.5 \mathrm{~g}, 33 \%)$. Phenyl 3,4-dinitrobenzoate $(4.5 \mathrm{~g}, 0.016 \mathrm{~mol})$ and ethyl acetate $(80 \mathrm{ml})$ were placed in a flask and $10 \% \mathrm{Pd} / \mathrm{C}(0.45 \mathrm{~g})$ was added to the solution. The mixture was then stirred at $25^{\circ} \mathrm{C}$ for $72 \mathrm{~h}$ in $\mathrm{H}_{2}$. After filtration of $\mathrm{Pd} / \mathrm{C}$, ethyl acetate was evaporated to afford white solids. Recrystallization from a mixture of diethyl ether and $n$-hexane yielded PDAB crystals $(2.5 \mathrm{~g}, 68 \%)$. Melting point: $120^{\circ} \mathrm{C}$. Anal. Calcd. for $\mathrm{C}_{13} \mathrm{H}_{12} \mathrm{O}_{2} \mathrm{~N}_{2}$ : C, 68.40; H, 5.31; N, 12.27. Found: $\mathrm{C}, 67.98 ; \mathrm{H}, 5.01 ; \mathrm{N}, 11.83 .{ }^{1} \mathrm{H}$ NMR $\left(300 \mathrm{MHz}, \mathrm{DMSO}-d_{6}\right)$ : $\delta$ 7.5-7.35 (m, $2 \mathrm{H}), 7.3-7.2(\mathrm{~m}, 3 \mathrm{H}), 7.2-7.1(\mathrm{~m}, 2 \mathrm{H}), 6.6-6.5(\mathrm{~d}, 1 \mathrm{H}), 5.55-5.4$ (s, 2H), 4.8-4.65 (s, 2H). IR (KBr, cm $\left.{ }^{-1}\right): 3447,3364,3057,2924,2854,1695$, $1621,1589,1519,1491,1446,1313,1286,1219,1200,1162,1073,942,910,819$, $760,744,688$.

\section{Polymerization}

DBT $(20 \mathrm{ml})$ was placed into a cylindrical flask and then heated up to $350^{\circ} \mathrm{C}$ under a slow stream of $\mathrm{N}_{2}$. DABA $(0.26 \mathrm{~g}, 1.72 \mathrm{mmol})$ was added to the solvent at $350{ }^{\circ} \mathrm{C}$ with stirring. The concentration for polymerization was $1.0 \%$, which was defined as the ratio of calculated polymer weight ( $\mathrm{g}$ ) to solvent volume (ml). Stirring was stopped when DABA was entirely dissolved, and the mixture was heated at $350^{\circ} \mathrm{C}$ for $20 \mathrm{~h}$. The precipitate was collected by filtration at $350^{\circ} \mathrm{C}$ to avoid the precipitation of oligomers on the crystals during cooling. The collected precipitate was washed with $n$-hexane and acetone, and then dried under a vacuum at $50^{\circ} \mathrm{C}$ for $12 \mathrm{~h}$. The filtrate was allowed to cool at $25^{\circ} \mathrm{C}$ and then poured into $n$-hexane. The precipitated oligomers, which were dissolved in the solvent at $350^{\circ} \mathrm{C}$, were collected by filtration, washed with $n$-hexane and dried. Polymerizations under other conditions were carried out in a similar manner.

In the polymerizations of $\mathrm{DAcBA}$ and $\mathrm{PDAB}$, these monomers were placed with DBT into a cylindrical flask at $25^{\circ} \mathrm{C}$, and then the mixture was heated up to $350^{\circ} \mathrm{C}$ under a slow stream of $\mathrm{N}_{2}$ with stirring. Stirring was stopped when the monomers were entirely dissolved, and then polymerization was carried out in a manner similar to the polymerization of DABA.

\section{RESULTS AND DISCUSSION}

\section{Polymerization of DABA and DAcBA}

LPF could not be used for the polymerization of DABA and DAcBA, because these two monomers were insoluble in LPF even at $350{ }^{\circ} \mathrm{C}$. Polymerizations of DABA were carried out in DBT at $350^{\circ} \mathrm{C}$ for $20 \mathrm{~h}$ with varying concentrations of $1.0-10.0 \%$. The results are presented in Table 1. Polymerization started immediately with eliminating water after the addition of DABA at $350{ }^{\circ} \mathrm{C}$ and then the solution became turbid by phase separation. When the concentration was $1.0 \%$, no precipitate was obtained. When polymerizations were carried out at concentrations ranging from 3.0 to $10.0 \%$, a brownish precipitate was finally obtained with yields of $6-15 \%$. The precipitates were spheres having plate-like crystals on their surface, as shown in Figure 1a. The average diameter of these spheres was $3.7 \mu \mathrm{m}$. The chemical structure of the precipitates was analyzed by IR spectroscopy as shown in Figure 2a. Characteristic peaks of PBI were clearly observed at $1625 \mathrm{~cm}^{-1}$ (imidazole ring), $1553 \mathrm{~cm}^{-1}(\mathrm{C}=\mathrm{C}, \mathrm{C}=\mathrm{N}), 1432 \mathrm{~cm}^{-1}$ 
(imidazole ring), $1289 \mathrm{~cm}^{-1}(\mathrm{C}-\mathrm{N})$ and $814 \mathrm{~cm}^{-1}(\mathrm{~N}-\mathrm{H})$. This spectrum is identical to that of previously prepared $\mathrm{PBI} .{ }^{32}$ However, a weak peak of $\mathrm{C}=\mathrm{O}$ stretching of a carboxyl end group was observed at $1700 \mathrm{~cm}^{-1}$. The inherent viscosities of the precipitates were in the range of $0.04-0.12 \mathrm{dlg}^{-1}$, suggesting low MW. A wide-angle X-ray

\section{Table 1 Results of polymerization of DABA and DAcBA}

\begin{tabular}{|c|c|c|c|c|c|}
\hline \multirow[b]{2}{*}{ Run no. } & \multicolumn{2}{|c|}{ Polymerization condition ${ }^{a}$} & \multirow[b]{2}{*}{ Yield (\%) } & \multirow[b]{2}{*}{$\eta_{i n h}{ }^{\mathrm{b}}\left(d / g^{-1}\right)$} & \multirow[b]{2}{*}{ Morphologyc } \\
\hline & Monomer & Concentration (\%) & & & \\
\hline 1 & DABA & 1.0 & 0 & & \\
\hline 2 & DABA & 3.0 & 6 & 0.04 & SP \\
\hline 3 & DABA & 5.0 & 12 & 0.12 & SP \\
\hline 4 & DABA & 10.0 & 15 & 0.09 & SP \\
\hline 5 & DAcBA & 0.5 & $<1$ & & \\
\hline 6 & DAcBA & 1.0 & 12 & 0.05 & Not clear \\
\hline
\end{tabular}

Abbreviations: DABA, 3,4-diaminobenzoic acid; DAcBA, 3,4-diacetoamidebenzoic acid. apolymerizations were carried out in DBT at $350^{\circ} \mathrm{C}$ for $20 \mathrm{~h}$.

bInherent viscosity $\left(\eta_{\text {inh }}\right)$ was measured in $97 \%$ sulfuric acid at $0.2 \mathrm{~g} \mathrm{dl}^{-1}$ at $30^{\circ} \mathrm{C}$.

cSP stands for spheres having plate-like crystals on surface. scattering profile of the precipitates is shown in Figure 3a. Four sharp peaks were observed at $2 \theta$ of $9.1^{\circ}(d$-spacing $=0.97 \mathrm{~nm}), 15.9^{\circ}$ $(0.56 \mathrm{~nm}), 18.5^{\circ}(0.48 \mathrm{~nm})$ and $24.3^{\circ}(0.37 \mathrm{~nm})$, which were assignable according to the previously reported orthorhombic unit cell of PBI crystals as noted in Figure 3. ${ }^{33}$ Although a broad halo contributed by an amorphous region was observed with sharp reflection peaks, the precipitates possessed high crystallinity. The precipitates collected after polymerization in DBT at $5.0 \%$ for 30 min constituted spheres with a smooth surface as shown in Figure 1b. This morphological change implies a formation mechanism of the spheres having plate-like crystals on their surface as follows: The spheres with a smooth surface are initially formed by liquid-liquid phase separation because of the low solubility of oligomers. The spheres are solidified by an increase in the MW of the oligomers within them. The concentration of oligomers in the dilute phase decreases by the precipitation of oligomers, leading to an increase in the MW of precipitated oligomers. This increase in the MW of precipitated oligomers alters the phase separation mode from liquid-liquid phase separation to crystallization in the middle of the polymerization. Thereafter, oligomers crystallize on the surface of the spheres to form plate-like crystals and spheres with plate-like crystals on their surface are finally obtained.
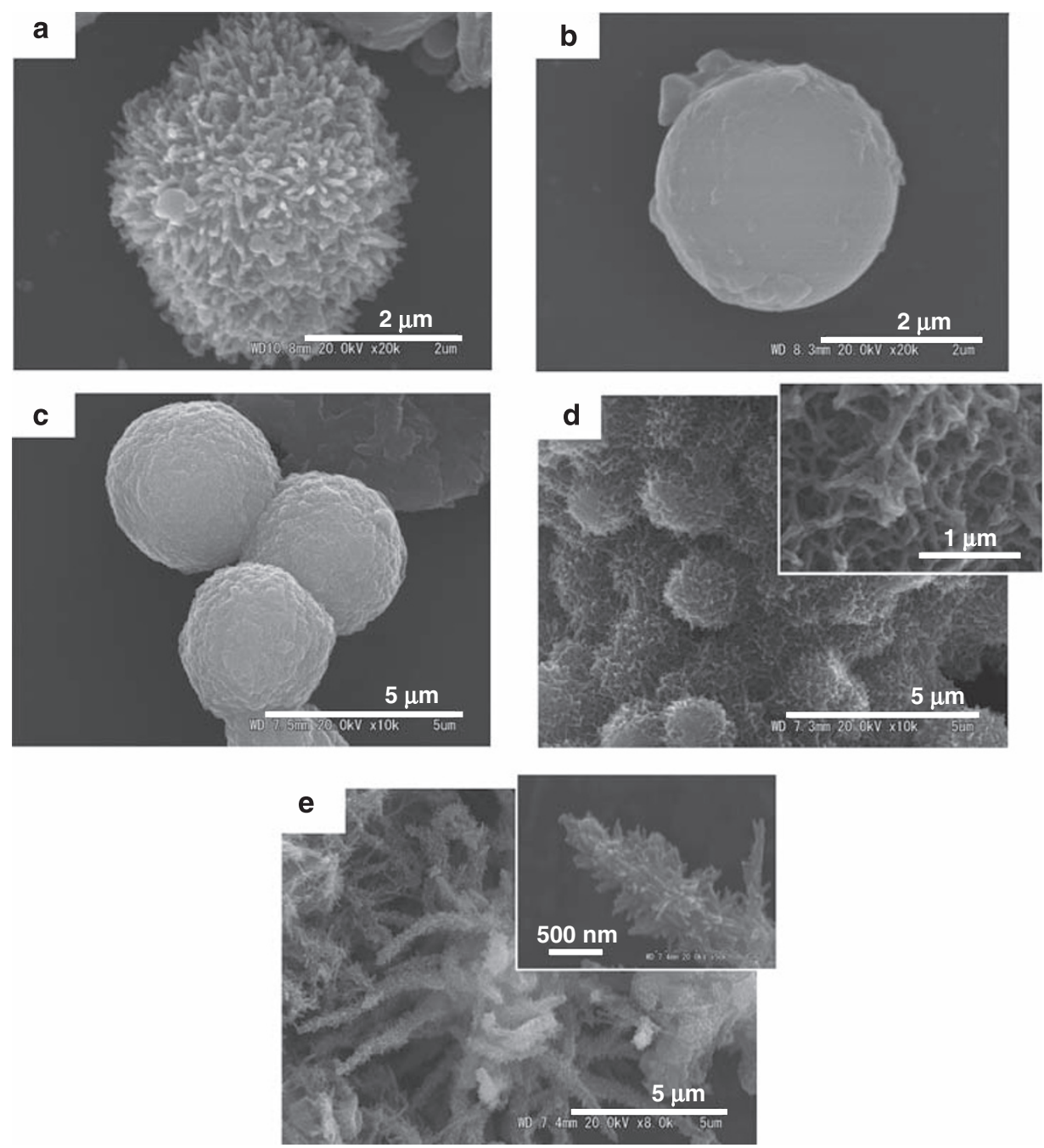

Figure $1 \mathrm{PBI}$ precipitates prepared from (a) DABA in DBT at a concentration of $5.0 \%$ for $20 \mathrm{~h}$ (run no. 3), (b) DABA in DBT at a concentration of $5.0 \%$ for 30 min, (c) PDAB in LPF at a concentration of $1.0 \%$ for $20 \mathrm{~h}$ (run no. 7), (d) PDAB in DBT at a concentration of $1.0 \%$ for $20 \mathrm{~h}$ (run no. 9) and (e) PDAB in DBT at a concentration of $3.0 \%$ for $20 \mathrm{~h}$ (run no. 11 ). 
Polymerizations of DAcBA were also carried out in DBT at $350{ }^{\circ} \mathrm{C}$ for $20 \mathrm{~h}$ at concentrations of 0.5 and $1.0 \%$. These results are also presented in Table 1. Polymerization started with eliminating acetic acid. Although the solution became slightly turbid, nothing was precipitated through polymerization at a concentration of $0.5 \%$. The solution became turbid and two immiscible liquid phases appeared at a concentration of $1.0 \%$. The dense liquid phase solidified

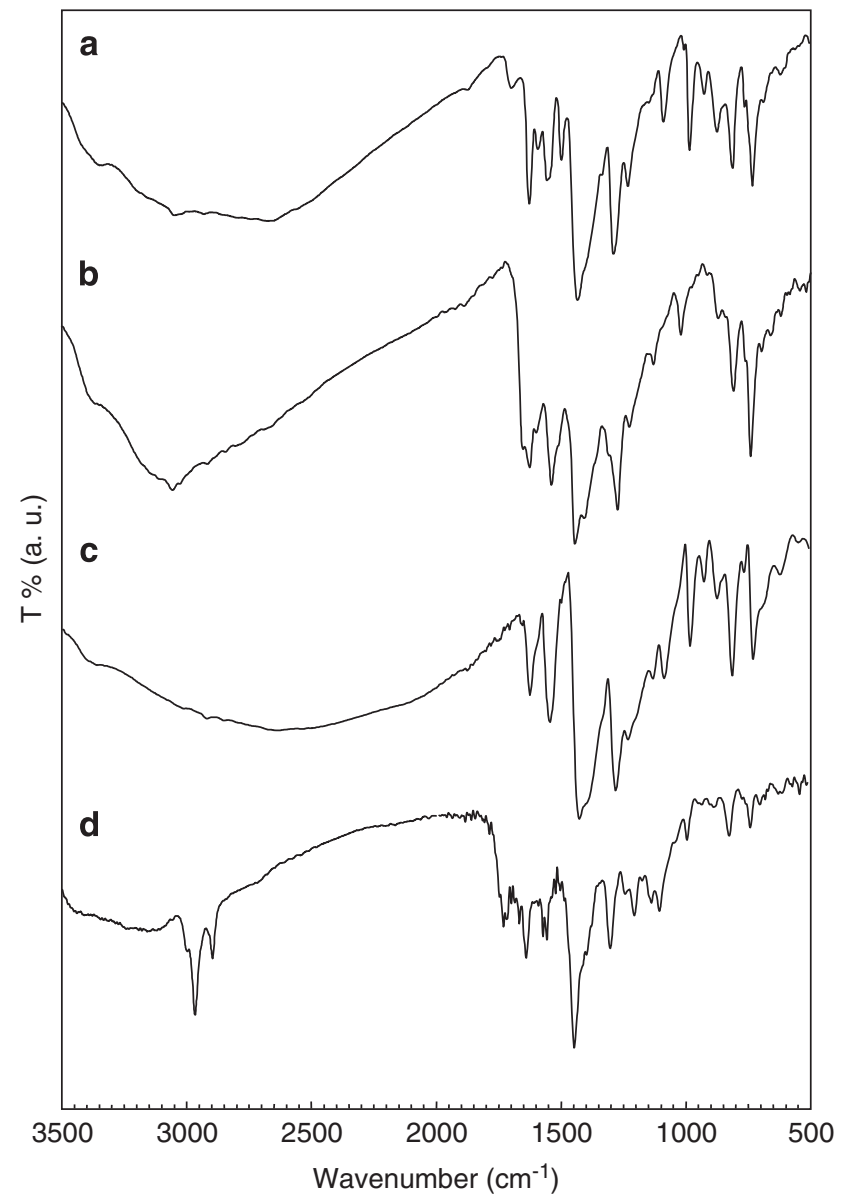

Figure $2 \mathrm{IR}$ spectra of $\mathrm{PBI}$ precipitates prepared from (a) DABA in DBT at a concentration of $5.0 \%$ for $20 \mathrm{~h}$ (run no. 3), (b) DAcBA in DBT at a concentration of $1.0 \%$ for $20 \mathrm{~h}$ (run no. 6), (c) PDAB in DBT at a concentration of $1.0 \%$ for $20 \mathrm{~h}$ (run no. 9) and (d) PDAB in DBT at a concentration of $1.0 \%$ for $1 \mathrm{~h}$. with polymerization, and dark brown polymer masses with unclear morphology were obtained at a yield of $12 \%$ after $20 \mathrm{~h}$. The inherent viscosity of the precipitates was $0.05 \mathrm{dlg}^{-1}$. The IR spectrum of the precipitates in DBT at a concentration of $1.0 \%$ for $20 \mathrm{~h}$ (run no. 6 ) is shown in Figure 2b. Characteristic peaks of PBI were clearly observed at $1627,1539,1445,1273$ and $809 \mathrm{~cm}^{-1}$. However, a peak of $\mathrm{C}=\mathrm{O}$ stretching of an amide linkage was observed as a shoulder at $1650 \mathrm{~cm}^{-1}$. Further, a slight peak of N-H stretching of an amide linkage was observed at $3050 \mathrm{~cm}^{-1}$. This fact suggests that phaseseparated oligomers comprise of both cyclized and uncyclized moieties. It also suggests that the cyclization reaction occurred very slowly to form the imidazole ring with the elimination of acetic acid. This structural irregularity of oligomers lowers the freezing temperature and reduces the crystallizability of oligomers, bringing about the liquid-liquid phase separation. The slow cyclization reaction disrupts the spherical morphology during the solidification of the dense liquid phase, resulting in an unclear morphology.

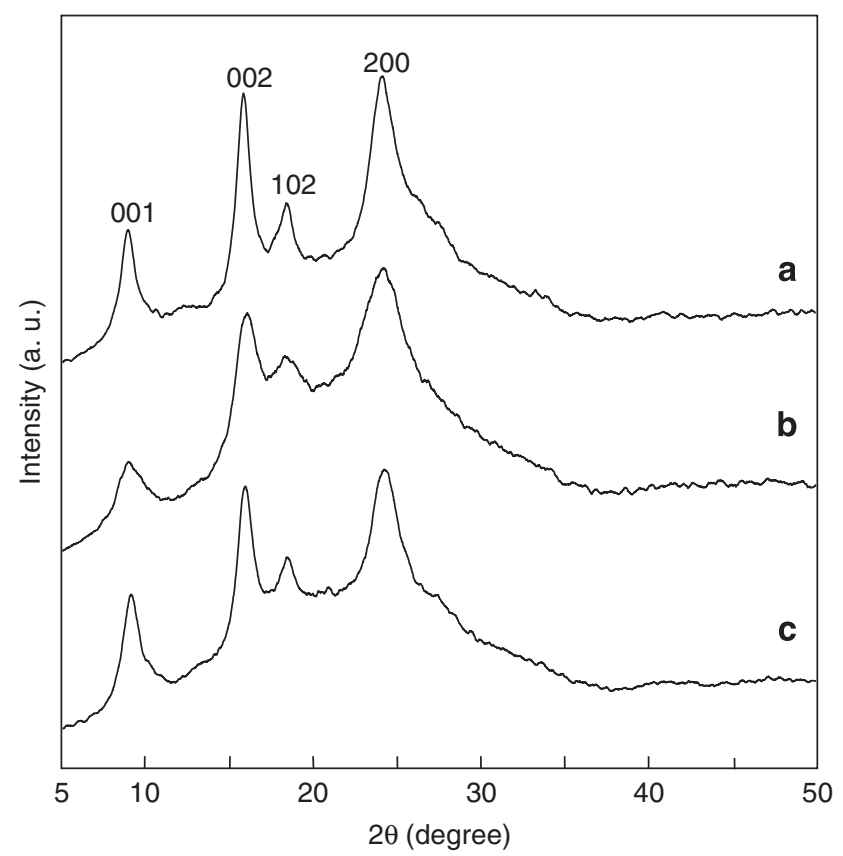

Figure 3 Wide-angle $\mathrm{X}$-ray scattering intensity profiles of $\mathrm{PBI}$ precipitates prepared from (a) DABA in DBT at a concentration of $5.0 \%$ for $20 \mathrm{~h}$ (run no. 3), (b) PDAB in LPF at a concentration of $1.0 \%$ for $20 \mathrm{~h}$ (run no. 7) and (c) PDAB in DBT at a concentration of $1.0 \%$ for $20 \mathrm{~h}$ (run no. 9).

Table 2 Results of polymerization from PDAB

\begin{tabular}{|c|c|c|c|c|c|c|c|c|}
\hline \multirow[b]{2}{*}{ Run no. } & \multicolumn{2}{|c|}{ Polymerization condition ${ }^{a}$} & \multirow[b]{2}{*}{ Yield (\%) } & \multirow[b]{2}{*}{$\eta_{i n h^{\mathrm{b}}}\left(d / g^{-1}\right)$} & \multirow[b]{2}{*}{ Morphology } & \multicolumn{2}{|c|}{ Average diameter } & \multirow[b]{2}{*}{$T_{d 10^{c}}\left({ }^{\circ} \mathrm{C}\right)$} \\
\hline & Solvent & Concentration (\%) & & & & Sphere $(\mu m)$ & Fiber $(n m)$ & \\
\hline 7 & LPF & 1.0 & 39 & 0.27 & Sphere & 3.9 & & 431 \\
\hline 8 & DBT & 0.5 & 36 & 0.76 & Fiber & & 48 & 637 \\
\hline 9 & DBT & 1.0 & 53 & 0.70 & Fiber & & 46 & 644 \\
\hline 10 & DBT & 2.0 & 90 & 0.36 & Fiber, brush & & 49 & 634 \\
\hline 11 & DBT & 3.0 & 94 & 0.27 & Brush & & & 637 \\
\hline
\end{tabular}

Abbreviations: DBT, dibenzyltoluene isomers; LPF, liquid paraffin; PDAB, phenyl 3,4-diaminobenzoate; TGA, thermogravimetric analysis.

apolymerizations were carried out at $350^{\circ} \mathrm{C}$ for $20 \mathrm{~h}$.

bInherent viscosity $\left(\eta_{\text {inh }}\right)$ was measured in $97 \%$ sulfuric acid at $0.2 \mathrm{gdl}^{-1}$ at $30^{\circ} \mathrm{C}$

cTemperature of $10 \%$ weight loss measured by TGA at a scanning rate of $20^{\circ} \mathrm{C} \mathrm{min}^{-1}$ in $\mathrm{N}_{2}$. 


\section{Polymerization of PDAB}

As previously mentioned, PBI prepared from DABA yielded spheres with plate-like crystals on the surface and they were formed by liquidliquid phase separation at the initial stage of polymerization. This liquid-liquid phase separation is induced because of the low solubility of oligomers in DBT. The solubility of oligomers should be enhanced to induce crystallization throughout polymerization, and therefore PDAB was used as a monomer for PBI. PDAB was soluble in both LPF and DBT at $350^{\circ} \mathrm{C}$, and polymerizations were carried out in both

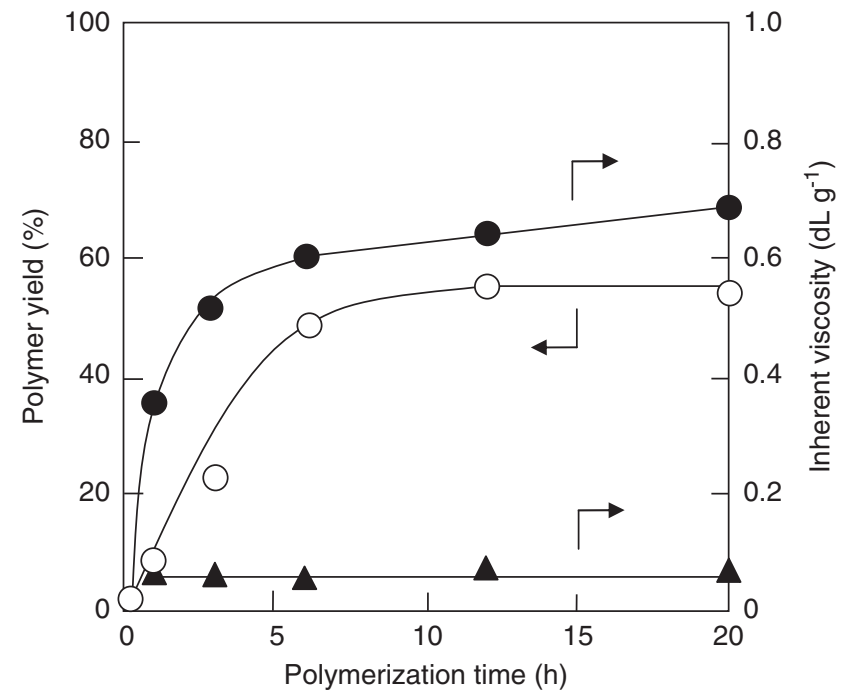

Figure 4 Polymerization of PDAB was carried out in DBT at a concentration of $1.0 \%$. Plots of yield $(O)$ and inherent viscosity $(\bullet)$ of the PBI precipitate and the inherent viscosity of oligomers $(\boldsymbol{\Lambda})$ as a function of polymerization time. solvents at $350^{\circ} \mathrm{C}$ for $20 \mathrm{~h}$. The results are presented in Table 2 . Polymerization started at $\sim 220^{\circ} \mathrm{C}$ with the elimination of phenol and water. Brown spheres were obtained at a yield of $39 \%$ by polymerization at a concentration of $1.0 \%$ in LPF as shown in Figure 1c. The average diameter was $3.9 \mu \mathrm{m}$ and the inherent viscosity was $0.27 \mathrm{dlg}^{-1}$. This morphological feature indicates that the phenyl ester end group of the oligomers could not enhance solubility sufficiently enough to induce crystallization in LPF. A brown precipitate was also obtained in DBT at concentrations of $0.5-3.0 \%$ with yields of 36-90\%. The inherent viscosities ranged from 0.27 to $0.76 \mathrm{dlg}^{-1}$. Both the yield and viscosity of the precipitates from PDAB were higher than those from DABA and DAcBA. As the $\mathrm{PDAB}$ concentration increases, the yield of the precipitate also increases, whereas its inherent viscosity decreases. When polymerization was carried out at concentrations of $0.5-2.0 \%$, aggregates of PBI fibers with an average diameter of $\sim 60 \mathrm{~nm}$ were formed, as shown in Figure 1d. These aggregates of PBI nanofibers show a network structure similar to that of a nonwoven fabric. The IR spectrum of the nanofibers is shown in Figure 2c, and it is identical to that of PBI. At the higher concentration of $3.0 \%$, the morphology changed from aggregates of nanofibers to brush-like crystals, which were similar to the crystals of poly[2,2'-(1,4-phenylene)-5,5'-bibenzimidazole], as shown in Figure $1 e^{28}$ Wide-angle X-ray scattering profiles of the precipitates are shown in Figures $3 \mathrm{~b}$ and $\mathrm{c}$. These profiles indicate that the products possess crystallinity as high as that of products prepared from DABA. The crystallinity of the spheres prepared in LPF was lower than that of other spheres. The thermal stability of these products was measured by thermogravimetric analysis in $\mathrm{N}_{2}$. Although the temperature of $10 \%$ weight loss $\left(\mathrm{T}_{\mathrm{d} 10}\right)$ of the spheres prepared in LPF is $431{ }^{\circ} \mathrm{C}$, that of the other products is in the range of $634-644^{\circ} \mathrm{C}$. Thus, the aggregates of nanofibers and brush-like crystals exhibit excellent thermal stability.
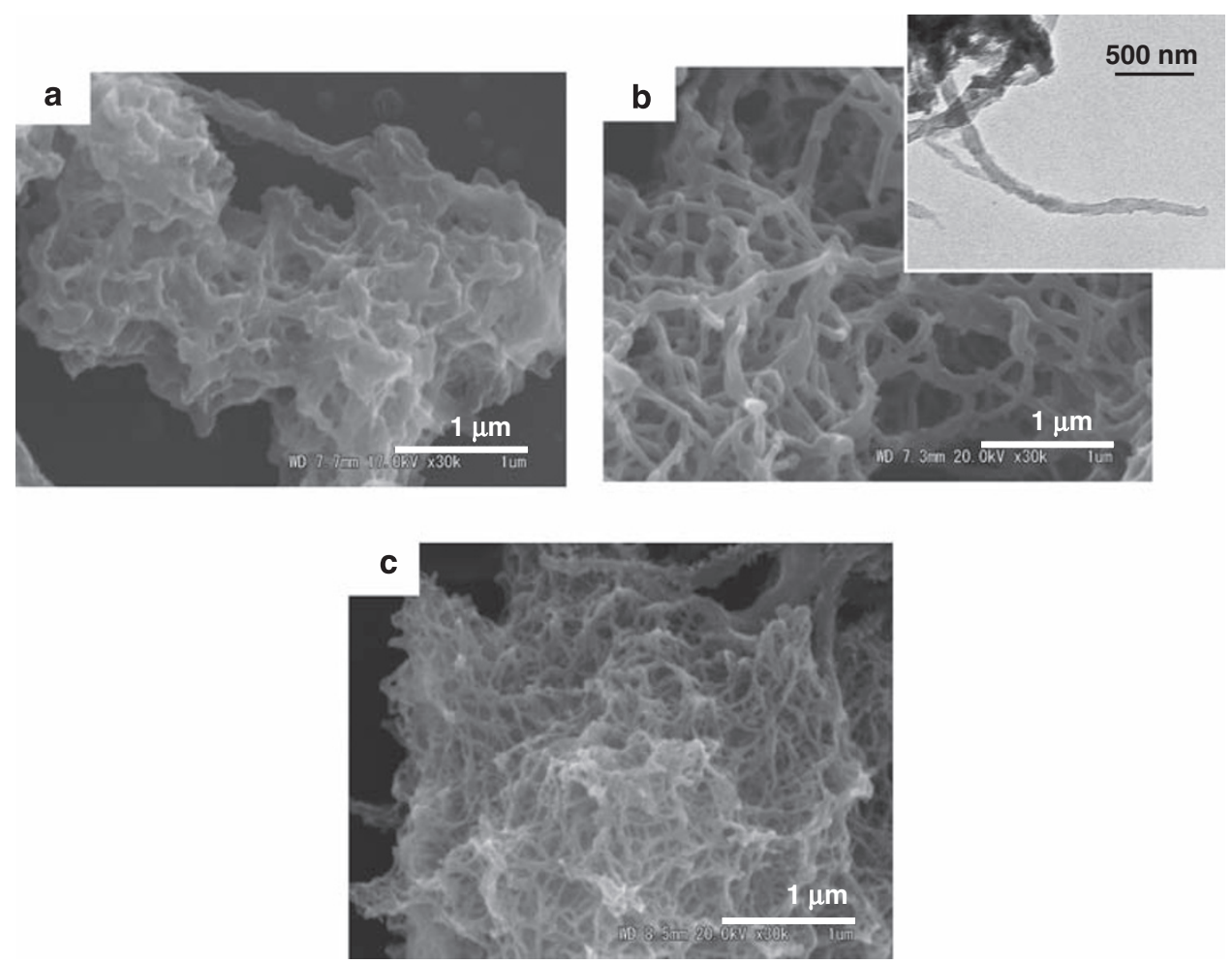

Figure $5 \mathrm{PBI}$ precipitates prepared from PDAB in DBT at a concentration of $1.0 \%$ for (a) $15 \mathrm{~min}$, (b) $1 \mathrm{~h}$ and (c) $3 \mathrm{~h}$. 


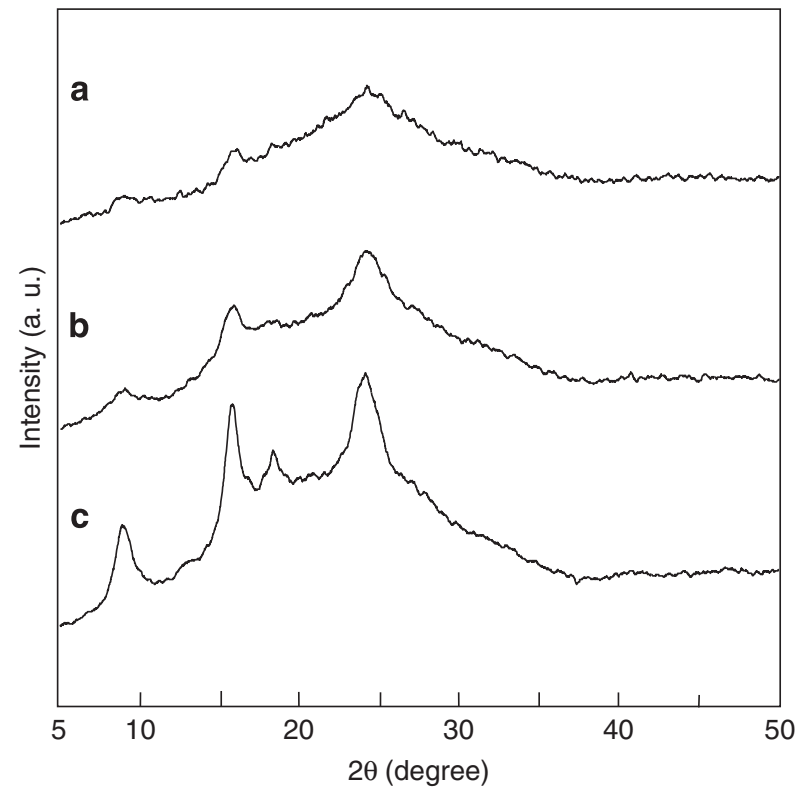

Figure 6 Wide-angle $\mathrm{X}$-ray scattering intensity profiles of $\mathrm{PBI}$ precipitates prepared from PDAB in DBT at a concentration of $1.0 \%$ for (a) $1 \mathrm{~h}$, (b) $6 \mathrm{~h}$ and (c) $12 \mathrm{~h}$.
The yield and viscosity of the PBI nanofibers were investigated during the polymerization of PDAB in DBT at a concentration of $1.0 \%$ at $350{ }^{\circ} \mathrm{C}$ to clarify the formation feature. They are plotted in Figure 4 as a function of time with the viscosity of the oligomers recovered from the solution. The yield increased with viscosity until $6 \mathrm{~h}$ and then both increased more gradually until $10 \mathrm{~h}$. The yield became constant after $10 \mathrm{~h}$, whereas the viscosity of precipitates increased slightly after the yield leveled off. This slight increase in viscosity indicates solid-state polymerization in the crystal. The viscosity of oligomers recovered from the solution was almost constant throughout polymerization. The precipitates obtained after $1 \mathrm{~h}$ were analyzed by IR spectroscopy. In the IR spectrum shown in Figure 2d, in addition to the characteristic PBI peaks, peaks characteristic of phenyl ester end groups were observed at $2850-2950 \mathrm{~cm}^{-1}$ (aromatic C-H), $1720 \mathrm{~cm}^{-1}$ (ester $\mathrm{C}=\mathrm{O}$ ) and $1195 \mathrm{~cm}^{-1}$ (ester $\mathrm{C}-\mathrm{O}-\mathrm{C}$ ). These results show that the precipitate initially comprises low-molecular-weight oligomers, and then the MW increases with polymerization between oligomers on and in the crystals. Polymerization in the crystal occurs very slowly at the last stage of polymerization because the molecular chains lose their mobility because of the increase in MW, which prevents the reaction between the end groups of the polymers in the crystal. The morphological changes are shown in Figure 5. Network aggregates of undeveloped plate-like or rod-like crystals were observed after $15 \mathrm{~min}$. They developed into fibers after $1 \mathrm{~h}$ with an average diameter

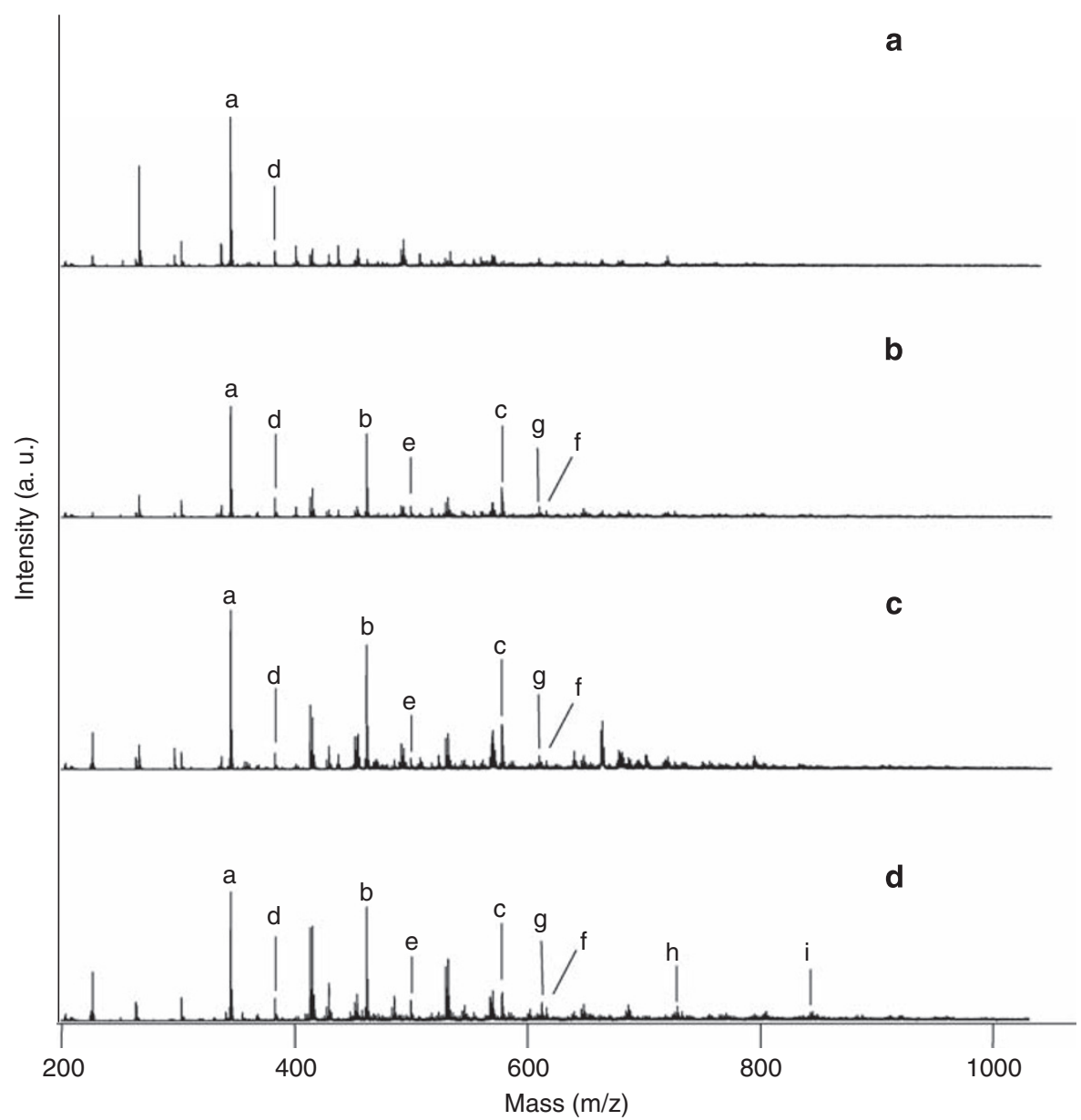

Figure 7 Matrix-assisted laser desorption ionization time-of-flight mass spectra of oligomers recovered from solution. Polymerizations of PDAB were carried out at a concentration of $1.0 \%$ (a) in LPF for $1 \mathrm{~h}$, (b) in LPF for $20 \mathrm{~h}$, (c) in DBT for $1 \mathrm{~h}$ and (d) in DBT for $20 \mathrm{~h}$. 
of $86 \mathrm{~nm}$. Thereafter, the average diameter decreased to $46 \mathrm{~nm}$ with time. It was difficult to measure the length of the fibers because they were entangled with one another, but the length seemed to increase with polymerization time. Spherical cores were not observed in the central part of the nanofiber aggregates, suggesting that nanofibers are not formed by liquid-liquid phase separation. The wide-angle X-ray scattering profiles of these crystals are summarized in Figure 6. The diffraction peaks of PBI prepared for $1 \mathrm{~h}$ were quite weak and a broad halo from the amorphous region remained. Even though an amorphous halo was observed, the diffraction peaks became shaper and the crystals developed with time. A selected-area electron diffraction was examined to clarify the molecular orientation in the fiber. It was difficult to take a selected-area electron diffraction of the aggregates of nanofibers because the fibers entangled densely. Although a selected-area electron diffraction pattern could be taken from the nanofibers prepared for $1 \mathrm{~h}$, only a diffuse halo was observed, and a clear diffraction pattern was not obtained to determine the molecular orientation because of low crystallinity as discussed above. These results imply that the fibers formed at the initial stage of polymerization did not possess a well-developed crystal structure and that they were fibrillar aggregates rather than crystal fibers. The crystal structure developed gradually with time in the fibers and they changed to crystalline fibers.

The oligomers left in the solution at $350{ }^{\circ} \mathrm{C}$ were collected from the solution after $1 \mathrm{~h}$ and $20 \mathrm{~h}$, and analyzed by matrix-assisted laser desorption ionization time-of-flight mass spectrometry. The spectra and peak assignments are shown in Figure 7 and Table 3, respectively. In LPF, only oligomers up to trimers were detected through polymerization and they were oligoimidazoles. Oligomers larger than tetramers are phase separated through a super-saturated state by liquid-liquid phase separation to form spheres. In contrast to this, oligomers up to tetramers were detected after $1 \mathrm{~h}$, and oligomers up to heptamers were detected after $20 \mathrm{~h}$ in DBT. Uncyclized oligomers were weakly detected after $20 \mathrm{~h}$, but many of them were also

Table 3 Structural assignment of peaks of oligomers prepared from PDAB in MALDI-TOF mass spectra

$\operatorname{Mass}(\mathrm{m} / \mathrm{z})$

\section{Peak code ${ }^{a}$}

$\mathrm{n}$

1

2

3

1

383.61

2

499.74

3

615.87

616.38

$\mathrm{K}^{+}$<smiles>CNc1ccc(C(=O)Nc2cccc(C(=O)Oc3ccccc3)c2)cc1N</smiles> 
oligoimidazoles. The oligoimidazoles larger than pentamers are phase separated at the early stage of polymerization to form nanofibers, in which the crystalline structure is not developed. The MW of phaseseparated oligomers increases with polymerization, and then the oligoimidazoles larger than octamers are phase separated by crystallization at the last stage of polymerization with developing crystal structure. Crystallization is induced in DBT because precipitated oligoimidazoles have a higher MW than that in LPF.

\section{CONCLUSION}

The morphology of PBI was drastically influenced by the chemical structure of monomers and the polymerization conditions. The polymerization of DABA in DBT afforded spheres with plate-like crystals on their surface. This spherical morphology might be formed by liquid-liquid phase separation. Polymerization of DAcBA yielded almost no precipitate because of the high solubility of oligomers. By contrast, polymerization of PDAB yielded a precipitate with a clear morphology. Spheres with a smooth surface were formed in LPF; the average diameter was $3.7 \mu \mathrm{m}$. In DBT, aggregates of nanofibers were obtained, and the average diameter of nanofibers was $\sim 60 \mathrm{~nm}$. The structure of the nanofiber aggregates resembled that of a nonwoven fabric. These fibers were formed by the precipitation of oligoimidazoles and their subsequent polymerization with the developing crystal structure. The nanofibers exhibited excellent thermal stability. The monomer structure influenced the mode of reaction-induced phase separation, bringing about the drastic change in the morphology of the precipitates. The monomer structure was an important parameter for controlling morphology, and $\mathrm{PDAB}$ was preferable for preparing PBI nanofibers.

\section{ACKNOWLEDGEMENTS}

This study was partly supported by a Grant-in-Aid for Scientific Research (B) (no. 21350127) from the Ministry of Education, Culture, Sports, Science and Technology, Japan, and by the Mazda Foundation.

1 Vogel, H. \& Marvel, C. S. Polybenzimidazoles, new thermally stable polymers. J. Polym. Sci. 50, 511-539 (1961).

2 Iwakura, Y., Uno, K. \& Imai, Y. Polyphenylenebenzimidazoles. J. Polym. Sci., Part A 2, 2605-2615 (1964).

3 Imai, Y., Uno, K. \& Iwakura, Y. Polybenzazoles. Makromol. Chem. 83, 179-187 (1965).

4 Higgins, J. \& Marvel, C. S. Benzimidazole polymers from aldehydes and tetraamines. J. Polym. Sci., Part A 8, 171-177 (1970).

5 Gerber, A. H. Thermally stable polymers derived from 2,3,5,6-tetraaminopyridine. J. Polym. Sci., Polym. Chem. Ed. 11, 1703-1719 (1973).

6 Hedberg, F. L. \& Marvel, C. S. A new single-step process for polybenzimidazole synthesis. J. Polym. Sci., Polym. Chem. Ed. 12, 1823-1828 (1974).

7 Dudgeon, C. D. \& Vogl, O. Bisorthoesters as polymer intermediates. II. A facile method for the preparation of polybenzimidazoles. J. Polym. Sci., Polym. Chem. Ed. 16, 1831-1852 (1978).
8 Neuse, E. W. \& Loonat, M. S. Two-stage polybenzimidazole synthesis via poly(azomethine) intermediates. Macromolecules 16, 128-136 (1983).

9 Ueda, M., Sato, M. \& Mochizuki, A. Poly(benzimidazole) synthesis by direct reaction of diacids and diamines. Macromolecules 18, 2723-2726 (1985).

10 Neuse, E. W. Aromatic polybenzimidazoles. Syntheses, properties, and applications. Adv. Polym. Sci. 47, 1-42 (1982).

11 Jackson, R. H. PBI fiber and fabric-properties and performance. Text., Res. J. 48, 314-319 (1978).

12 Coffin, D. R., Serad, G. A., Hicks, H. L. \& Montgomery, R. T. Properties and applications of Celanese PBI—polybenzimidazole fiber. Text., Res. J. 52, 466 (1982).

$13 \mathrm{Kim}$, J.- S. \& Reneker, D. H. Polybenzimidazole nanofiber produced by electrospinning. Polym. Eng. Sci. 39, 849-857 (1999)

14 Kim, C., Park, S.-H., Lee, W.-J. \& Yang, K.- S. Characteristics of supercapaitor electrodes of $\mathrm{PBI}$-based carbon nanofiber web prepared by electrospinning. Electrochimica Acta. 50, 877-881 (2004).

15 Lammers, M., Klop, E. A., Northolt, M. G. \& Sikkema, D. J. Mechanical properties and structural transitions in the new rigid-rod polymer fibre PIPD ('M5') during the manufacturing process. Polymer 39, 5999-6005 (1998).

16 Jenkins, S., Jacob, I. K., Polk, B. M., Kumar, S., Dang, T. D. \& Arnold, F. E. Structure, morphology, and properties of methyl-pendant poly( $p$-phenylene benzobisimidazole) and methyl-pendant poly( $p$-phenylene benzobisthiazole). Macromolecules $\mathbf{3 3}$, 8731-8738 (2000).

17 Dang, T. D. \& Arnold, F. E. Water soluble rigid-rod polymers. Polym. Preprint (Am. Chem. Soc., Div. Polym. Chem.) 33, 912-917 (1992).

18 Gieselman, M. B. \& Reynolds, J. R. Water-soluble polybenzimidazole-based polyelectrolytes. Macromolecules 25, 4832-4834 (1992).

19 Sansone, M. J. Preparation of $\mathrm{N}$-substituted polybenzimidazoles. U.S. Patent 4,898,917, 6 February (1990).

20 Klaehn, J. R., Luther, T. A., Orme, C. J., Jones, M. G., Wertsching, A. K. \& Peterson, E. $\mathrm{S}$. Soluble $\mathrm{N}$-substituted organosilane polybenzimidazoles. Macromolecules 40, 7487-7492 (2007).

21 Nephew, J. B., Nihei, T. C. \& Carter, S. A. Reaction-induced phase separation dynamics: a polymer in a liquid crystal solvent. Phys. Rev. Lett. 80, 3276-3279 (1998).

22 Tran-Cong, Q. \& Harada, A. Reaction-induced ordering phenomena in binary polymer mixtures. Phys. Rev. Lett. 76, 1162-1165 (1996).

$23 \mathrm{Kyu}$, T. \& Lee, J. H. Nucleation initiated spinodal decomposition in a polymerizing system. Phys. Rev. Lett. 76, 3746-3749 (1996).

24 Williams, R. J. J., Rozenberg, B. A. \& Pascault, J. P. Reaction-induced phase separation in modified thermosetting polymers. Adv. Polym. Sci. 128, 95-156 (1997).

25 Luo, K. The morphology and dynamics of polymerization-induced phase separation. Eur. Polym. J. 42, 1499-1505 (2006).

26 Wang, X., Okada, M., Matsushita, Y., Furukawa, H. \& Han, C. C. Crystal-like array formation in phase separation induced by radical polymerization. Macromolecules $\mathbf{3 8}$, 7127-7133 (2005).

27 Kimura, K., Kohama, S. \& Yamazaki, S. Morphology control of aromatic polymers in concert with polymerization. Polym. J. 38, 1005-1022 (2006).

28 Gong, J., Kohama, S., Kimura, K., Yamazaki, S. \& Kimura, K. Preparation of brush-like crystals of poly. Polymer 49, 3928-3937 (2008).

29 Wakabayashi, K., Kohama, S., Yamazaki, S. \& Kimura, K. Nonstoichiometric synthesis of poly $\left(4,4^{\prime}\right.$-oxydiphenylene pyromelliteimide) by reaction-induced crystallization of oligomers. Macromolecules 41, 1168-1174 (2008).

30 Kimura, K., Nakajima, D., Kobashi, K., Kohama, S., Uchida, T. \& Yamashita, Y. Morphology control of poly(p-mercaptobenzoyl) by modification of oligomer endgroup. Polym. J. 37, 471-479 (2005).

31 Kimura, K., Kurihara, Y., Ohmori, H., Kohama, S., Yamazaki, S. \& Yamashita, Y. Morphological architecture of poly(p-oxybenzoyl) by modification of oligomer endgroup. Polymer 48, 3429-3436 (2007).

32 Gies, P., Nonidez, W. K., Anthamatten, M., Cook, R. C. \& Mays, J. M. Characterization of an insoluble polyimide oligomer by matrix-assisted laser desorption/ionization time-of-flight mass spectrometry. Rapid Commun. Mass Spectrom. 16, 1903-1910 (2002).

33 Stephen J. Krause, S. J., Haddock, T., Price, G. E., Lenhert, P. G., O'brien, J. F., Helminiak, T. E. \& Adams, W. W Morphology of a phase-separated and a molecular composite PBT/ABPBI polymer blend. Polym. Sci., Part B 24, 1991-2016 (1991). 